\title{
A noite branca, entre o documental e o ficcional: a memoria silenciada da División Azul
}

\author{
A noite branca, between the Documentary and Fictional: \\ the Silenced Account of the Blue Division
}

\author{
Dolores ViLAVEDRa \\ Universidade de Santiago de Compostela \\ Departamento de Filoloxía Galega \\ dolores.vilavedra@usc.es
}

[recibido 30/07/2015, aceptado 10/09/2015]

\section{RESUMO}

O artigo indaga na ambigua condición fenomenolóxica da novela $A$ noite branca de Francisco Fernández Naval, publicada en galego en 2012, ambigüidade producida tanto pola súa hibridez discursiva coma polo difuso estatuto ontolóxico dos feitos narrados e de varios personaxes. O esclarecemento das estratexias coas que se constrúe a devandita ambigüidade, xunto á orixinalidade do tema, no conxunto de textos narrativos galegos que abordan a memoria da Guerra Civil e a Posguerra, permite valorar atinadamente os méritos literarios da novela.

PALABRAS CHAVE: Memoria, Guerra Civil, Narrativa galega, Literatura epistolar, Literatura documental, División Azul.

\section{RESUMEN}

El artículo indaga en la ambigua condición fenomenológica de la novela $A$ noite branca (La noche blanca) de Francisco Fernández Naval, publicada en gallego en 2012, ambigüedad producida tanto por su hibridez discursiva como por el difuso estatuto ontológico de los hechos narrados y de varios personajes. El esclarecimiento de las estrategias con las que se construye dicha ambigüedad, junto a la originalidad del tema, en el conjunto de textos narrativos gallegos que abordan la memoria de la Guerra Civil y la Posguerra, permite valorar ajustadamente los méritos literarios de la novela.

PALABRAS CLAVE: Memoria, Guerra Civil, Narrativa gallega, Literatura epistolar, Literatura documental, División Azul.

\begin{abstract}
The article explores the ambiguous phenomenological status of the novel $A$ noite branca (The White Night) by Francisco Fernández Naval, published in Galician in 2012. This ambiguity is produced by the discursive hybridity of the novel and by the vague ontological status of facts narrated and by several characters. The clarification of the strategies of the said ambiguity, and the originality of the subject, in the whole of Galician narrative about the memory of Civil War and Postwar can tightly evaluate the literary merits of the novel.
\end{abstract}

KEYwORDS: Memory, Civil War, Galician Narrative, Epistolary Literature, Documentary Literature, Blue Division.

Vilavedra, D. (2015): “A noite branca, entre o documental e o ficcional: a memoria silenciada da División Azul”, Madrygal. Revista de Estudios Gallegos (Madr.), 18: 147-155.

SUMARIO: 1. Introdución. 2. Cartas, blog, novela... 3. Do documental ao ficcional: o difuso estatuto fenomenolóxico do epistolar. 4. Referencias bibliográficas. 


\section{INTRODUCIÓN}

En 2012 Francisco Fernández Naval publicou $A$ noite branca, unha longa novela que xira arredor da experiencia dos voluntarios galegos na División Azul. O interese que o tema podía suscitar en Galicia, se temos en conta que uns 3000 galegos formaron parte do continxente, así como a súa orixinalidade no ámbito da literatura galega, víronse acrecentados polo feito de que o autor fose no seu día un dos pioneiros da abordaxe na nosa lingua do tema da Guerra Civil con $O$ bosque das antas ${ }^{1}$. Esta novela case fundacional foi merecente en 1988 do prestixioso Premio Xerais, o que testemuña a rápida canonización do asunto nun proceso que axiña se vería reforzado pola concesión dese e outros importantes galardóns a outras obras sobre o tema (Vilavedra 2010: 246). Ese carácter de pioneiro sen dúbida dotaba ao escritor Fernández Naval dun plus de lexitimidade á hora de abordar calquera asunto relacionado coa memoria histórica galega.

Certamente, a orixinalidade do tema actuou como un muro de contención fronte ao risco de sobreexplotación ou desgaste desa memoria. Na medida en que a literatura funciona como un espazo social de circulación das memorias parciais e silenciadas, e na medida en que novos suxeitos se incorporan á memoria colectiva ${ }^{2}$, evítase o esquecemento ou a marxinación de certos grupos de vítimas e vitimarios, así como a fixación pasatista con determinados motivos temáticos e a súa repetición ritualizada, pois cómpre non esquecer que a elaboración social da memoria dun grupo permite a súa reinterpretación. No caso da División Azul, eu diría que en Galicia (e en España) estamos aínda un paso máis atrás, nunha fase previa a esa hipotética reinterpretación pois primeiro sería preciso que a sociedade actual soubese da existencia desa unidade de voluntarios, cuxa memoria deveu nun verdadeiro tabú, antes de que esa memoria sexa susceptible de ser sometida a novas interpretacións, alén das que se están a producir no ámbito especializado (e, polo mesmo, restrinxido) dos estudos históricos (como exemplo véxase infra a nota a rodapé 5). A literatura pode converterse así nunha eficaz ferramenta para conseguir que as sociedades se enfronten dialecticamente co seu pasado en toda a súa complexidade e, polo tanto, co seu presente e os valores que neste se están a promover.

Un bo exemplo do descoñecemento ao que me acabo de referir atopámolo na ausencia, no debate público sobre a cuestión da localización e recuperación dos corpos dos represaliados, de informacións coma esta:

En septiembre de 1995 el Gobierno socialista firma un convenio con la fundación alemana Volksbund, especializada en la búsqueda de desaparecidos de la $2^{\mathrm{a}}$ guerra mundial, con el objeto de localizar los restos de los miembros de la División Azul fallecidos en tierras rusas al servicio del nazismo. Hasta la fecha [2000] y por un costo de 130.000 euros, van localizados dos mil cadáveres. (Espinosa 2006: 184)

Tantas páxinas de xornal escritas sobre os nunca atopados restos de Lorca e case ninguén disposto a lembrar eses case 5000 soldados caídos $^{3}$ tan lonxe do seu país...

\footnotetext{
${ }^{1}$ De feito, en A noite branca aparecen espalladas aquí e acolá algunhas referencias a personaxes daquela novela (véxanse por exemplo as páxinas 52 ou 124). Non é este o lugar para comentalas, só apuntar que, dada a súa irrelevancia argumental, que as volve absolutamente innecesarias, coido que se pode formular a hipótese de que cumpren a función de ancorar a novela na modalidade xenérica de 'novelas da Guerra Civil' ou 'da memoria histórica', de vencellala a esa xenealoxía de textos na que $O$ bosque das antas ocupa unha posición case fundacional.

${ }^{2}$ Utilizo o concepto de xeito aberto, no ronsel conceptual de Halbwachs e tal como foi empregado, e repensado, por Assmann e outros. Unha glosa operativa para o uso que aquí se lle dá pódese atopar en Amalio Blanco e en Maldonado.

${ }^{3}$ Tomo este dato de http://memoriablau.foros.ws/. A cifra non inclúe feridos, mutilados nin prisioneiros.
} 


\section{CARTAS, BLOG, NOVELA...}

Arredor da orixe e creación da novela $A$ noite branca hai unha serie de feitos que a singularizan e que complican (no mellor senso da palabra) o estatuto fenomenolóxico do texto e dos sucesos que nel se contan. En primeiro lugar, o feito de que a trama argumental está directamente inspirada nun feixe de cartas asinadas no seu día por un parente do escritor Francisco Fernández Naval e atopadas por este setenta anos despois. Curiosamente, este dato fúrtasenos nos paratextos, malia aludirse neles a unhas cartas que aparentemente formarían parte propiamente da ficción. Só descubrimos que esas cartas teñen existencia empírica (ou, máis ben que hai unhas cartas que teñen existencia empírica) cando, no ronsel da publicación da novela, empeza a sinalarse ese dato nas diversas entrevistas que se lle realizan ao autor. Coñecido isto, xorden os interrogantes: as cartas, son transcrición unhas (as ficticias) das outras (as reais)? Ou simplemente Fernández Naval inspírase, para redactar aquelas, nese material epistolar realmente existente? As cartas reais están asinadas por Alfredo Rodríguez, o protagonista da novela? Existiu ese home? Pero, sobre todo, por que se nos agocha esa información? De que estratexia literaria forma parte esa decisión? Porque non me parece moi ousado afirmar que a opción do escritor Fernández Naval é unha opción literaria que leva implícitas unha serie de consecuencias no ámbito da recepción:

- Ao non confesar explicitamente a existencia dun corpus epistolar real co que a novela mantén unha certa relación, é perfectamente posible imaxinar que o público (ou certo público) lea a novela ignorando a existencia dese corpus e, polo tanto, coa convicción de que as cartas incluídas en A noite branca son un material pura e estritamente ficticio.

- Un caso distinto é o daqueles públicos que saben ou intúen que as cartas da novela manteñen certa relación cunhas cartas reais pero que se atopan con que non se explicita o tipo nin grao desa relación. Eses lectores poden supor que a presenza das cartas se debe a unha transcrición pero, en todo caso, imponse o descoñecemento do tipo de relación transtextual (en termos genettianos) que mantén o epistolario ficcional co real, polo que finalmente se potencia unha recepción ambigua, cando menos no referido á condición fenomenolóxica tanto do propio epistolario como do que nel se narra, ambigüidade que condicionará a interpretación global do narrado e, en consecuencia, dos feitos históricos nos que a novela se inspira: a historicidade da División Azul dilúese nesa ambigüidade.

Estas consecuencias non son casuais, nin froito do caprichoso xorne das musas. Non. $\mathrm{O}$ escritor toma certas decisións porque pretende conseguir uns determinados obxectivos literarios, porque pretende evitar certos efectos ou por ambas razón a un tempo. E a máis importante desas decisións, na miña opinión, é ancorar con rotundidade o relato, sen posibilidade de dúbida mais tamén sen renunciar ás vantaxes que a verdade histórica lle ofrece, no eido da ficción. Veremos máis adiante algunhas das estratexias ás que Fernández Naval recorre para conseguir ese obxectivo.

En segundo lugar, o blog ${ }^{4}$ que o autor abriu en La Voz de Galicia (o xornal de maior tirada de Galicia) para narrar (antes de publicar a novela) a viaxe que o levaría, xunto coa súa dona, dende A Coruña ás proximidades de Leningrado seguindo as pegadas que en 1941 deixara o primeiro continxente de voluntarios galegos por Europa adiante. Fernández Naval reproducirá, setenta anos despois, etapa a etapa, ese percorrido. A primeira entrada do blog é do 25 de marzo de 2011, e di así:

Na vida, ás veces, algo chama por nós desde un tempo esquecido, desde un lugar afastado. Podemos atender ou non a ese sinal, pero cando dentro de nós sentimos que o chamar nos

${ }^{4}$ http://blogs.lavozdegalicia.es/degaliciaanovgorod/. 
conmove e que a súa forza se mantén constante, debemos responder e, se é posible, acudir.

Nunca pensamos dedicarlle esforzo ou atención á División Azul. Era ese un eco de infancia alleo a nós, tanto por pensamento, como por emoción ou complicidade. Pero a aparición dunha caixa de marmelo coas cartas e fotografías que un parente, Alfredo Rodríguez, lle escribía aos pais dende a "Fronte do leste" provocou que, por primeira vez, a nosa atención se fixase nese momento crucial da historia. Para ben ou para mal, Alfredo estivo nun dos lugares nos que se decidía o futuro, que é como dicir o que nós somos hoxe. Iso espertou a nosa curiosidade e interese.

Seguiremos, polos camiños de Europa, dende Galicia a Novgorod, diante do río Volchov, o ronsel dos seus pasos e, con el, os da primeira quenda de voluntarios que saíu de España en xullo de 1941. Prestaremos particular atención á memoria dos divisionarios galegos dos que temos coñecemento. Pero tamén estaremos atentos ao que imos ver, á xente coa que imos falar e daremos conta da impresión que producen en nós as cidades e as paisaxes descubertas.

A viaxe fornecería sen dúbida materiais e inspiración abondos para a ficción; de feito, varias entradas do blog adiantan episodios que logo aparecerán só un chisco máis desenvoltos na novela. Vexamos algún exemplos:

- Os tres últimos parágrafos da entrada do 27 de marzo no blog, onde se narran varias peripecias do convoi divisionario ao seu paso por Lugo, Astorga e Hendaya, reprodúcense exactamente nas páxinas 64-65 da novela.

- O 28 de marzo de 2011, chegados os viaxeiros ao campamento de Grafenwöhr, o blog evoca o xuramento de fidelidade ao Führer que a División Azul fixera o 31 de xullo de 1941 nese mesmo lugar, xuramento que na novela se reconstrúe no capítulo VI. Ese mesmo día 28 o escritor-viaxeiro Fernández Naval coñece nunha cervexería un curioso individuo chamado Thomas que presenta numerosos puntos de contacto co Thomas Mohr personaxe, tal e como se nos aparece no capítulo V. O mesmo sucede co Martin que coñece en Karlsruhe, moi semellante ao rapaz así chamado co que o Alfredo-personaxe traba conversa ao paso da expedición por esa mesma cidade (pp. 73-76).
- A entrada do 30 de marzo sintetiza a escena das páxinas $64-65$, onde se evoca o apedreamento do continxente en varias estacións francesas por parte de exiliados e traballadores do ferrocarril. Dende aí, o bucle intertextual lévanos ata o diario do comandante Claudio Rivera, xefe da expedición $n^{\circ} 14$ que trasladou o continxente galego, e que será aludido varias veces como fonte tanto no blog como na novela (p. 64), fonte á que o autor chega grazas á información e materiais que lle proporciona, segundo o seu alter ego Marcos confesa e como axiña comentarei, o historiador Xosé Manuel Núñez Seixas.

O blog revélase así non só como a crónica dunha viaxe senón, dende a perspectiva que a nós nos interesa, como un caderno de traballo, un laboratorio onde experimentar con materiais reais que logo se converterán -ou nonen novelescos. Mais iso, no momento en que o blog se está a publicar, ninguén o sabe; se cadra, nin o propio autor. E aí este atopa un novo atranco, á hora de equilibrar o estatus do real e o ficticio: refírome ao proceso de ficcionalización no que entran certos materiais documentais ao seren incorporados á diéxese. $\mathrm{O}$ caso da referencia ao informe do comandante Claudio Rivera, xefe da expedición dos voluntarios galegos, é un bo exemplo: o lector ou lectora non avisada pode perfectamente xulgar que o tal comandante é un personaxe literario, que nunca existiu dito informe e, polo tanto, que a escena que supostamente ese informe comenta, a do apedreamento dos trens, é unha invención autorial. É dicir, o valor documental que certos materiais tiñan no blog transmútase na novela en valor estritamente literario.

Para evitar que a novela perda completamente ese valor documental, tan cotizado na modalidade xenérica á que se adscribe $A$ noite branca, Fernández Naval introduce fontes verificables como a alusión a "O meu amigo Seixas, historiador especializado no tema, facilitoume fotografías e documentos que me permitiron unha primeira aproximación" ao tema (p. 64): certos públicos competentes identificarán tras esta alusión ao historiador galego Xosé Manuel Núñez Seixas, autor efectivamente de importantes estudos sobre a División Azul ${ }^{5}$. Mais tamén é certo que outra interpretación 
posible desa referencia é considerala como un mero operador realista ${ }^{6}$. Ao cabo, imporase a primeira interpretación, cando na longa lista de dedicatorias que pecha $A$ noite branca o historiador aparece de primeiro. Mais, nese xogo de equilibrios entre o documental e o ficional, entre o verificable e o que non o é, a novela agocha -por exemplo- a existencia de documentación sobre un dos personaxes máis citados e que realmente existiu e sobreviviu: o sarxento Grande, quen foi entrevistado por X. M. Núñez Seixas o 22 de decembro de 1987. Esta entrevista está transcrita e figura co $\mathrm{n}^{\mathrm{o}} 25$ no Arquivo Historga (Historia Oral de Galicia) da Universidade de Santiago de Compostela e nela podemos atopar, entre outras curiosidades, unha escena ${ }^{7}$ que sen dúbida inspirou a do barbeiro Levi Korczak na novela (véxase o capítulo VII).

A gran pregunta que $A$ noite branca formula é, na miña opinión, a seguinte: dispondo dun material tan valioso como as cartas do seu parente o divisionario Alfredo Rodríguez, que move a Fernández Naval a reconverter ese epistolario nunha obra de ficción e non limitarse a transcribilo, quizais acompañado dunha introdución histórica ou en todo caso lexitimando en referencia a rodapé a súa autenticidade? Haberá quen diga que a inspiración de escritor, ou que esa é unha decisión perfectamente lexítima que non precisa de ningunha explicación, e certamente é así. Podemos logo abordar a cuestión dende outra perspectiva: non a da intencionalidade -sempre subxectiva e, polo mesmo, sempre discutible- senón dende a dos resultados. Que efectos estéticos consegue o autor coa devandita reconversión?
Cales poden ser as súas consecuencias na orde ética?

\section{DO DOCUMENTAL AO FICCIONAL: O DIFUSO ESTATUTO FENOMENOLÓ- XICO DO EPISTOLAR}

A continuación, e para tentar respostar cando menos parcialmente a estes interrogantes desenvolverei a hipótese de que a integración das cartas nun contexto ficcional lle permite ao autor, traballando por oposición fenomenolóxica, obxectivar ou, dito doutro xeito, dotar dunha certa historicidade a un material de natureza radicalmente subxectiva como é o epistolar. Dita integración semella así unha solución de compromiso entre as distorsións que o tratamento ficcional pode levar a cometer cun material narrativo como o que está na orixe d'A noite branca, e a falaz obxectividade que podería atribuírselle a un corpus dese tipo, pola simple feito da súa existencia empírica. Fernández Naval desprega logo un amplo abano de estratexias narrativas coherentes con estes obxectivos. Centrareime na análise de dúas desas estratexias que se desenvolven en estreita relación:

- A dualidade temporal presente/pasado na que se move o discurso narrativo promove unha interpretación de este que integra o tratamento rigoroso dos coñecementos historiográficos e a sensibilidade contemporáneas.

- A literaturización dos materiais documentais permite desenvolver unha visión afectiva e moral do pasado, en principio pouco compatible coa distancia propia do oficio do historiador.

\footnotetext{
${ }^{5}$ Véxase entre outros Núñez Seixas (2005, 2006 e 2008).

${ }^{6}$ Tomo o concepto de Anxo Tarrío, quen o define como "estratexias narrativas [...] que conforman un alarde de saber minucioso que presta unha grande autoridade ao narrador sobre a historia e sobre o que o lector non pode pronunciarse senón soamente crer con boa fe cooperadora. A miúdo son datos que en nada inflúen no relato de seu [e que] teñen unha función pragmática subliminal poñendo un marchamo de realismo ao narrado" (1989: 117): son habituais os datos familiares, numéricos, xeográficos ou relativos a fontes.

${ }^{7}$ Transcribo: "nunha vila de Polonia había un barbeiro sefardí que falaba español sefardita, e que se puxo moi contente cando encontrou españois e puido falar en español connosco, así que fomos todos a cortar o pelo onda el".
} 
A estrutura d'A noite branca ven determinada pola transcrición do epistolario dun tal Alfredo Rodríguez Naval, que se inicia o 12 de xullo de 1941 e cuxas cartas aparecen salferidas ao longo da novela mais non de xeito aleatorio senón actuando como marco que abre e pecha cada capítulo. Estes (vinteún en total), numerados en romanos, presentan unha organización interna tripartita: cada un dos tres bloques narrativos que forman cada capítulo ten un tempo propio e un estatuto enunciativo diferente, que se repite de capítulo a capítulo.

O primeiro bloque é sempre un discurso en $3^{\mathrm{a}}$ persoa ao cargo dun narrador omnisciente que vai relatando as peripecias dun grupo formado polos que pouco a pouco imos intuíndo que son voluntarios da División Azul, así como as persoas que van coñecendo e coas que se van relacionando; Alfredo, o autor das cartas, forma parte dese grupo. Aínda que moi próximo aos feitos narrados, a condición extradiexética do narrador permítelle situarse nunha certa atemporalidade e incorporar outros puntos de vista como o dun xornalista, Miro Álvarez, quen na ficción viaxara a Riga para facer unha reportaxe sobre a División Azul e entrevistara a Alfredo durante a convalecencia deste no hospital.

No segundo escoitamos un discurso en $1^{\mathrm{a}}$ persoa, en estilo indirecto libre, centrado na rememoración da vida da propia narradora a quen iremos identificando e ubicando na rede de relacións familiares que subxace na trama xeral da novela e que remata por ser a nai de Alfredo. Por distintas referencias internas chegamos a saber que esa muller, María Luísa, morre nos primeiros meses de 1960, con setenta anos. O seu discurso iniciase aí, unhas semanas antes do seu pasamento, e ten como narratarias unhas veciñas que decote a convidan a xantar: ese é o momento en que agroman esas lembranzas.

No terceiro bloque escoitamos outra voz que nos fala en $1^{a}$ persoa mais agora é a dun tal Marcos, sobriño-neto de María Luísa, que, a partir da descuberta dunha caixa coas devanditas cartas e outros materiais (facturas, fotografías, documentos de identificación...), emprende o que el mesmo denomina "un in- tenso exercicio de memoria" (p. 83), xunto coa súa nai, "procurando lembranzas nos máis afastados recunchos do seu pasado, buscando recordos que nos permtisen reconstruír a historia de María Luísa e do seu fillo Alfredo" (p. 83).

Para reforzar a simetría desta estrutura, todas as intervencións de Marcos rematan cunha referencia a un vello amigo da infancia, Saúl, que no presente da enunciación é alférez do exército español. O seguimento das peripecias de Saúl case en tempo real, ata a súa morte nun atentado terrorista en Afganistán (p. 333) semella ter unha función actualizadora da reflexión sobre a guerra pois lémbranos que, ao cabo, o mundo pouco mudou, e que a violencia bélica ao servizo dos intereses dos poderosos segue a causar vítimas inocentes. Mais dende unha perspectiva exclusivamente narrativa, na miña opinión, a introdución da historia de Saúl non está lograda pois resulta moi descompensada en comparación con outras historias secundarias (como a de Katia e Yuri, por exemplo). Posiblemente concibida para realizar unha función contrapuntística, en todo caso resultaría funcional para introducir un vector de comparación entre a fe de Saúl na causa pola que combate "ofrecendo a súa inocencia de cruzado por unha causa que considera xusta" (p. 311), e o pragmatismo ideolóxico de Alfredo, cuxos móbiles últimos para alistarse como voluntario non acabamos de coñecer.

Do tal Marcos intuímos xa case dende o principio que debe ter afeccións literarias, pois un dos seus curmáns propón que "o mellor é darlle a caixa a Marcos, a ver se fai unha novela" (p. 25). E pouco máis adiante recoñece que "non me atraía nada a idea de escribir sobre a División Azul", aínda que aceptara "o compromiso de ver que posibilidades había de contar unha historia", a partir do contido da tal caixa (p. 43). Marcos insinúasenos como unha sorte de trasunto ficcional do propio autor empírico Francisco X. Fernández Naval: pola coincidencia do segundo apelido podemos sospeitar que este tamén portiña con Alfredo, como Marcos; por outra banda, ambos están casados cunha muller chamada Isabel (se ben alcumada Sabela a dona de Marcos e Maribel 
a do escritor) e ambos teñen un fillo chamado Daniel. A partir desta serie de coincidencias, un dos desafíos que a novela lle lanza ao público lector é dilucidar canto de histórico hai no epistolario e no relato da xenealoxía familiar no que aquel se integra. A ambigüidade do estatuto fenomenolóxico do narrado - de todo o narrado, non só do epistolario- confírmase así como unha das claves da novela.

Polo que se refire á primeira cuestión (é dicir, o valor documental das cartas), Marcos confesa as fontes ás que recorre para documentarse sobre a División Azul, e mesmo comparte connosco (p. 120) referencias concretas como a do Diario de Operacións do II Batallón do Rexemento 269, no que se integrara Alfredo: este dato permítenos contrastar a información do epistolario cos rexistros do devandito Diario do Batallón ${ }^{8}$, e comprobar que coincide plenamente, o que sen dúbida reforza a historicidade das cartas que, como dixen, é un dos obxectivos da novela. O propio Marcos convídanos a facer tal cousa cando nos di que atopou o Diario "navegando por internet". Igualmente podemos comprobar a autenticidade das transcricións (pp. 245-246) que nos proporcionan varias entradas correspondentes a febreiro de 1942 do Diario de guerra do corpo do Exército 38 da Whermacht, material que lle fora proporcionado por Núñez Seixas e que este mesmo cita nos seus traballos de investigación (por exemplo, en 2008: 61).

Contra o final, Marcos vai buscando informantes que completen o cadro, a imaxe que fora forxando de Alfredo a través das cartas (mesmo chega a encargar un estudo grafolóxico destas), da documentación consultada e das lembranzas da súa propia nai. Poderiamos dicir que coa súa pesquisa e o seu discurso Marcos "socializa" a memoria de Alfredo, intégraa na colectiva, alén do ámbito persoal e familiar no que inicialmente a reconstrúe. Así, nese proceso de investigación fala con Eustaquio Puga, quen fora médico de cabeceira do propio Marcos e, de neno, veciño de Alfredo. Fala con Carlos Rey, fillo do divisionario Óscar Rey, por quen sabemos -a partir da súa propia experiencia filial- como se desenvolveu o retorno dos combatentes galegos dende Rusia e podemos logo imaxinar como foi o de Alfredo, retorno que ningunha das voces do relato nos narra. Fala tamén con Chus Cabado, filla do divisionario José Cabado: da autenticidade destas dúas testemuñas -Carlos e Chus- sabemos por figuraren os seus nomes na dedicatoria final. Ademais, Marcos transcribe (p. 353) un par de cartas de felicitación que o II Batallón recibiu en abril do 42 de altos mandos do exército alemán: a autenticidade desas cartas pódese corroborar na entrada correspondente ao 6 de abril do xa citado (véxase supra) diario de operacións que é, por outra banda, onde supomos que as atopa Marcos. A maiores, Marcos partilla connosco (p. 122) a información que supostamente lle foi remitida polo Arquivo Xeral militar de Ávila correspondente ao expediente militar de Alfredo; a referencia bibliográfica dunha monografía sobre o fotógrafo Francesc Catalá-Roca, que recolleu as imaxes dos últimos retornados da División, procedentes dos campos de concentración soviéticos en 1954; a da novela Pallarega de Marcelino Fernández Mallo (Toxosoutos, 2011), na que se fala dun tipo que pasara tres meses na División Azul e voltara "como durmido, como se debaixo das pálpebras se lle levantara unha tapia a proba de pensamentos" (p. 98) e ao diario dun tal José Ma Sánchez Diana (publicado en 2009 baixo o título Cabeza de puente. Diario dun soldado de Hitler), un soldado que realmente existiu pero que trasmutado en personaxe literario compartiu con Alfredo a convalecencia hospitalaria en Riga (véxanse pp. 386 e 408 e ss.). O relato flúe así entre o privado (Marcos e as súas pescudas) e o público, entre o individual e o colectivo e, unha vez máis, entre o ficcional e o real empírico, nunha dinámica de mutua retroalimentación entre ambos planos.

Pero a novela vai evoluíndo cara a María Luísa, tía avoa de Marcos e nai de Alfredo, un

${ }^{8}$ http://memoriablau.foros.ws/t150/diario-de-operaciones-del-ii-batallon-del-regimiento-269/. 
personaxe que cada vez cobra máis protagonismo. A súa historia devolve o relato ao ámbito da ficción e afonda na dimensión privada do personaxe de Alfredo. O propio Marcos, como narrador da súa parte, confesa que cada vez se sinte máis engaiolado pola súa figura (véxase, por exemplo, o que di nas páxinas 332-333). É María Luísa quen establece o vínculo entre o pasado de Alfredo e o presente de Marcos, dunha maneira moito máis "física": ela revélase como a encarnación material da memoria, na medida en que é a súa caixa de marmelo, con todo o que contén, a que permite que Marcos poña en marcha os mecanismos da postmemoria $^{9}$ (Hirsch 2000). O círculo péchase de vez cando na derradeira escena familiar evócase a morte de María Luísa, a partir das lembranzas da nai de Marcos e de Ramón, seu curmán, e fillo dunha das mulleres que coidou de María Luísa nos últimos meses da súa vida, unha das narratarias do seu discurso .

A diferenza do que acontece con Alfredo, non podemos verificar ata que punto a historia desa muller singular que foi María Luísa ten ou non un correlato real, ata que punto se inspira (ou non) na verdade histórica, pero tampouco importa porque a ficción vaille permitir ao autor abrir un espazo onde poidan operar con liberdade os mecanismos da subxectividade e a afectividade, moito máis limitados -pola procedencia histórica do material narrado- tanto no relato de Marcos como no do narrador omnisciente, ambos centrados nas peripecias de Alfredo e os seus compañeiros divisionarios.
E esta é a cuestión clave, o que explica que, dalgún xeito, Fernández Naval "malbarate" un valiosísimo material argumental: María Luísa podería ter sido, ela soa, a protagonista dunha magnífica novela. Mais o autor serviuse dela para dotar $A$ noite branca dunha maxia e dun poder de evocación que se cadra se vían un tanto coutados pola condición histórica dos avatares de Alfredo. Se son María Luísa e a súa historia os elementos que decantan $A$ noite branca do lado da ficción, é Marcos na súa actividade como narrador do bloque 3 quen lexitima o valor documental das cartas, e tamén quen outorga ese valor a diversos elementos que aparece no relato puramente ficticio (na medida en que é o de María Luísa o único dos que se entrecruzan na novela que non ofrece un estatuto fenomenolóxico vinculado dun ou doutro xeito co 'real' empírico) do bloque 2 e tamén no do narrador omnisciente do bloque 1: así, na p. 160 Marcos describe a revista Hoja de Campaña, cuxa colección completa di que puido consultar na biblioteca da Facultade de Historia e da que volve falar na páxina $380^{10}$ o narrador omnisciente cando adopta o punto de vista do xornalista Miro Álvarez. Por iso é tan importante que Marcos apareza como trasunto ficcional do autor Francisco. Fernández Naval: é este quen levou adiante o inxente labor de investigación que se percibe tras a novela... mais, ao tempo, non o esquezamos, Marcos é un personaxe de ficción: o protagonista dunha novela titulada $A$ noite branca. E para nós, lectores, iso debería ser abondo.

\footnotetext{
${ }^{9}$ A postmemoria establece unha conexión mediata co pasado, concretada case sempre nalgunha persoa pero ás veces nun obxecto (como a caixa e o seu contido) ou texto (unha carta, por exemplo); esa conexión establécese por medio non da colleita de pegadas (como adoita suceder coa memoria) senón polo pulo creativo e imaxinativo que alguén atopa nese pasado. Fronte á memoria, a postmemoria caracterízase pola distancia xeracional, e fronte á historia, pola íntima conexión persoal que implica, e é a experiencia propia daqueles que viron cortocircuitada a elaboración das súas propias narrativas polo peso das da xeración anterior, condicionada esta por algún acontecemento traumático que non foi quen de asimilar de xeito coherente (Hirsch 2000: 22).

${ }^{10}$ A información que ofrece Marcos é falsa pois na Facultade de Historia non existe ningún número da revista a disposición do público. Isto non invalida, na miña opinión, a pretensión (e eficacia) lexitimadora do que os narradores din sobre Hoja de campaña. A única biblioteca do Estado na que se pode consultar a colección completa é a da Universitat Pompeu Fabra, onde teñen unha reproducción facsímile de todos os números; case completa está a colección da Hemeroteca Municipal de Madrid. Agradezo a información a Francisco Redondo Aboal, bibliotecario da Facultade de Filoloxía da USC.
} 


\section{REFERENCIAS BIBLIOGRÁFICAS}

Blanco, Amalio (1997): "Los afluentes del recuerdo: la memoria colectiva", en J. Ma RuizVargas (comp.), Claves de la memoria. Madrid: Trotta.

Espinosa Maestre, Francisco (2006): Contra el olvido. Historia y memoria de la guerra civil. Barcelona: Crítica.

HIRSCH, Marianne (2000): Family frames. Photography, narrative and postmemory. Cambridge: Harvard University Press.

Maldonado Alemán, Manuel (2009): “Introducción”, en M. Maldonado (coord.), Literatura e identidad cultural. Representaciones del pasado en la narrativa alemana a partir de 1945. Bern: Peter Lang.

NúÑEz SeIXAs, Xosé Manuel (2005): "Los vencedores vencidos: la peculiar memoria de la División Azul, 1945-2005”, Pasado y memoria. Revista de Historia Contemporánea 4, pp. 83113.

(2006): "El Tercer Reich, la Wehrmacht y la División Azul 1941-1945: Memoria e imágenes contrapuestas", Ayer 69.1, pp. 47-72.

(2008): “¿Eran los rusos culpables? Imagen del enemigo y políticas de ocupación de la División Azul en el Frente del Este: 1941-1944”, Hispania 223 (maio-agosto), pp. 695-750.

TARrío, Anxo (1989): Álvaro Cunqueiro ou os disfraces da melancolía. Vigo: Galaxia.

VILAVEDRA, Dolores (2010): A narrativa galega na fin de século. Unha ollada crítica dende 2010. Vigo: Galaxia. 